\title{
MICROLEAKAGE AND MICROSHEAR BOND STRENGTH OF DIFFERENT TYPES OF DENTAL COMPOSITE RESTORATIVE MATERIALS
}

\author{
Mohamed I. Ebrahim* and Adel M. Shaaban**
}

\begin{abstract}
The present study was conducted to evaluate the microleakage and microshear bond strength of different types of dental composite. For microleakage test, 45 caries-free human permanent maxillary molars with no crack, decay, or structural deformities were collected. A standard Class $\mathrm{V}$ cavity was prepared on the buccal surface of each tooth. The cavity of each tooth was acid etched and the adhesive material was applied to the etched surface, gently dried and cured. The prepared teeth were divided randomly into three groups, (15 for each group) according to the types of composite. Group A: Tetric EvoCeram nanohybrid composite (Ivoclar vivadent Inc. USA and Canada), Group B: Tetric EvoCeram Bulk fill composite (Ivoclar vivadent Inc. USA and Canada) and Group C: Sonic Fill Bulk fill composite (Kerr Restoratives, USA). The specimens in each group were restored with the corresponding composite and cured according to manufacturer's instructions. The specimens were submitted to thermo-cycling, covered with nail varnish, followed by immersion in dye solution. Each tooth was sectioned longitudinally using hard tissue microtome. The microleakage was measured using digital microscope at $\times 10$ magnification. The dye penetration in the specimens was evaluated for both the occlusal and gingival surfaces based on a scoring system. Kruskal-Wallis test was used to determine the difference between microleakage scores in the three study groups at a 0.05 level of significance. For microshear bond strength test, 30 caries-free human permanent mandibular molars with no crack, decay, or structural deformities were collected. The occlusal surface of the teeth were ground perpendicular to the long axis of each tooth to expose a flat dentin surface. A dentine slice with thickness $2 \mathrm{~mm}$ was sectioned perpendicular to the long axis of each tooth. The surfaces of dentin slides were acid etched and the adhesive material was applied to the etched surface, gently dried and cured. The specimens were divided into three main groups (10 for each group) according to the type of composite resins used as in microleakage test. Composite resins was placed, cured and the specimens were submitted to thermocycling before testing. The recorded values of bond strengths in (MPa) were collected, tabulated and statistically analyzed. One way analysis of variance (ANOVA) and Tukey's tests were used for testing the significance between the means of tested groups. The results showed that Tetric EvoCeram nanohybrid composite had the highest scores of microleakage followed by Tetric EvoCeram Bulk fill and Sonic Fill Bulk fill which showed the lowest scores. The results also showed that Sonic Fill Bulk fill composite had the highest microshear bond strength value followed by Tetric EvoCeram Bulk fill and Tetric EvoCeram nanohybrid composite which showed the lowest value.
\end{abstract}

* Assistant Professor of Dental Biomaterials, Faculty of Dental Medicine Al Azhar University, Cairo (Boys).

** Lecture of Dental Biomaterials, Faculty of Dental Medicine Al Azhar University, Cairo (Boys). 


\section{INTRODUCTION}

Nearly half of all dental restorations fail within 10 years and replacing those accounts for $50-70 \%$ of all restorative dentistry ${ }^{1}$. Composites are popular filling materials because of their esthetics and directfilling capabilities ${ }^{2-8}$. However, composite tends to accumulate more biofilms than other restorative materials in vivo. Biofilms at the restoration margins could produce acids and cause secondary caries, the main reason for restoration failure ${ }^{19-13}$.

The polymerization of resin-based composites generates stresses due to their contraction during this process. Shrinkage stress occurs when the contraction is obstructed and the material is rigid enough to resist sufficient plastic flow to compensate for the original volume. The magnitude of contraction stresses is highly dependent on the visco-elastic properties of the material ${ }^{14}$. Clinically, these stresses may be transferred to the margins of the restoration, possibly affecting marginal quality ${ }^{15}$. When marginal quality is not adequate, problems like leakage, recurrent caries and pulpal irritation may occur ${ }^{16,17}$. Even by considering that an absolutely perfect marginal seal is not achievable clinically, a good marginal quality should be the main objective for clinicians. Restoration placement techniques are widely recognized as a major factor in the modification of shrinkage stresses ${ }^{18}$.

Nanocomposites have high filler loading that led to improved mechanical properties, high wear resistance, and reduced polymerization shrinkage . In addition to these advantages nanocomposites have excellent finishing and polishing qualities thus can be recommended as universal filling materials for anterior and posterior restorations. ${ }^{19}$

Bulk Fill composites possess specific characteristics, including enhanced flowability to achieve consistent adaptation to the cavity preparation. Elasticity and low polymerization shrinkage stress reduce microleakage, postoperative sensitivity and secondary caries. Improved depth of cure of at least $4 \mathrm{~mm}$ eliminates the need for layering ${ }^{20}$.

The recent introduction of the SonicFill (Kerr corp. USA) combines the attributes of a low viscosity composite and a universal composite. By activating the composite with sonic energy, it is possible to fill the cavity and adapt the low viscosity material easily, and then compact and model it while the composite changes its consistency until it reaches a higher viscosity. The advantages are reduced working time and polymerization shrinkage, better adaptation to cavity walls, and ease of use ${ }^{21}$.

The purpose of this study to evaluate the microleakage and microshear bond strength of nanohydrid, Tetric EvoCeram Bulk fill and Sonic Fill Bulk fill composites.

\section{MATERIALS AND METHODS}

Three different types of composite were used in this study nanohybrid composite Tetric EvoCeram (Ivoclar vivadent Inc. USA and Canada), Tetric EvoCeram Bulk fill (Ivoclar vivadent Inc. USA and Canada ) and Sonic Fill Bulk fill composite (Kerr Restoratives, USA) and one type adhesive Single Bond Universal Adhesive (3M ESPE, USA ) were used in this study.

\section{1- Microleakage test:}

Forty five human permanent maxillary molars with no crack, decay, or structural deformities were collected and stored in normal saline. After removing residual tissue tags, the specimens were cleaned with pumice. A standard Class V cavity with dimensions ( $3 \mathrm{~mm}$ mesiodistal width, $3 \mathrm{~mm}$ occlusogingival height and $2 \mathrm{~mm}$ depth) was prepared on the buccal surface of each tooth using a straight fissure diamond bur and the cavity was adjusted to an approximate depth of $2 \mathrm{~mm}$ using periodontal probe.

The cavity of each tooth was acid etched using $37 \%$ phosphoric acid gel for 15 seconds. Then the 
teeth were rinsed with water spray and dried with oil free stream. The adhesive material (Single Bond Universal Adhesive) was applied to the etched surface, gently dried and cured. The prepared teeth were divided randomly into three groups, 15 for each group according to the types of composite. Group A: Tetric EvoCeram nanohybrid composite (Ivoclar vivadent Inc. USA and Canada), Group B: Tetric EvoCeram Bulk fill composite (Ivoclar vivadent Inc. USA and Canada ) and Group C: Sonic Fill Bulk fill composite (Kerr Restoratives, USA). The specimens in each group were restored with the corresponding composite and cured according to manufacturer's instructions.

The specimens were submitted to 1000 thermal cycles at $5^{\circ} \mathrm{C}$ and $55^{\circ} \mathrm{C}$ with a dwell time of 30 seconds at each temperature then covered with two layers of nail varnish, except the resin composite restoration and $1 \mathrm{~mm}$ area around it, followed by immersion in dye solution ( $3 \%$ Methylene blue). ${ }^{20}$

Each tooth was sectioned longitudinally in the bucco-lingual direction at the center of the restoration using hard tissue microtome. The microleakage was measured using digital microscope at $\times 10$ magnification. The dye penetration in the specimens was evaluated for both the occlusal and gingival surfaces based on the following scoring system:

\section{Microleakage scores:}

* 0 - No dye penetration.

* 1 - Dye penetration involving less than half the occlusal/gingival wall .

* 2 - Dye penetration involving more than half the occlusal/gingival wall.

* 3 - Dye penetration involving the axial wall.

\section{2- Microshear bond strength test:}

Thirty human permanent mandibular molars with no crack, decay, or structural deformities were collected and stored in normal saline. After removing residual tissue tags, the specimens were cleaned with pumice. A dentin slice, approximately $2.0 \mathrm{~mm}$ thick, was cut perpendicular to the long axis of each tooth from the upper-middle coronal portion region using a low-speed diamond saw under water coolant. The occlusal surfaces of slices were ground with silicon carbide paper up to \#600 grit to expose a flat dentin surface..$^{22-25}$

The dentin slices were divided into three main groups (containing 10 each) according to the type of composite resins used. Group A: Tetric EvoCeram nanohybrid composite, Group B: Tetric EvoCeram Bulk fill composite and Group C: Sonic Fill Bulk fill composite.

Each dentin slice was acid etched using 37\% phosphoric acid gel for 15 seconds. Then the dentin slices were rinsed with water spray and dried with an oil-free stream for five seconds. The adhesive was applied on the dentin surface and air-thinned for 15 seconds. A gentle stream of dry air was applied to disperse the material into a thin, uniform, shiny surface and prior to curing, three or four cylinders (internal diameter: $0.7 \mathrm{~mm}$, height: $1.0 \mathrm{~mm}$ ) of Tygon $^{\circledR}$ microbore tubing (R-3603, Norton Performance Plastic Co., Cleveland, $\mathrm{OH}$ ) were placed on the flat dentin at different locations. The adhesive was then light-cured for 10 seconds with light emitting diodes LED (BG-light-LTD, 4002 Plovdiv, 430-490nm, Bulgaria).

After irradiation, each tube was filled with composite resins and then light-cured with the tip as close to the surface as possible. All restorations were finished and polished with a set of solfex discs (3M Company, St. Paul MN, USA). The specimens were stored in moist conditions at room temperature for one hour prior to removing the Tygon tubing.

The specimens were immersed in water at $37^{\circ} \mathrm{C}$ for 24 hours then subjected to thermocycling before testing to simulate clinical thermal stress conditions. The specimens were submitted to 1000 thermal cycles at $5^{\circ} \mathrm{C}$ and $55^{\circ} \mathrm{C}$ with a dwell time of 30 seconds at each temperature. 
The resin cylinders were then subjected to the microshear bond test, ${ }^{24}$ whose diagram is shown in Fig 1. Each dentin slice with the resin cylinders was placed in the lower attachment of the universal testing machine ( LRX-Plus II; Lloyd Instruments Ltd., Fareham, UK) for microshear bond testing. A thin wire (diameter $0.20 \mathrm{~mm}$ ) was looped around each resin cylinder, making contact through half of the cylinder base and was placed as close as possible to the resin-dentin interface. A shear force was applied to each specimen at a crosshead speed of $0.5 \mathrm{~mm} / \mathrm{min}$ until failure occurred. The resindentin interface of the specimens and the wire loop were aligned as straight as possible to ensure that the same orientation in shear was maintained. The loads at failure were recorded and the data were analyzed.

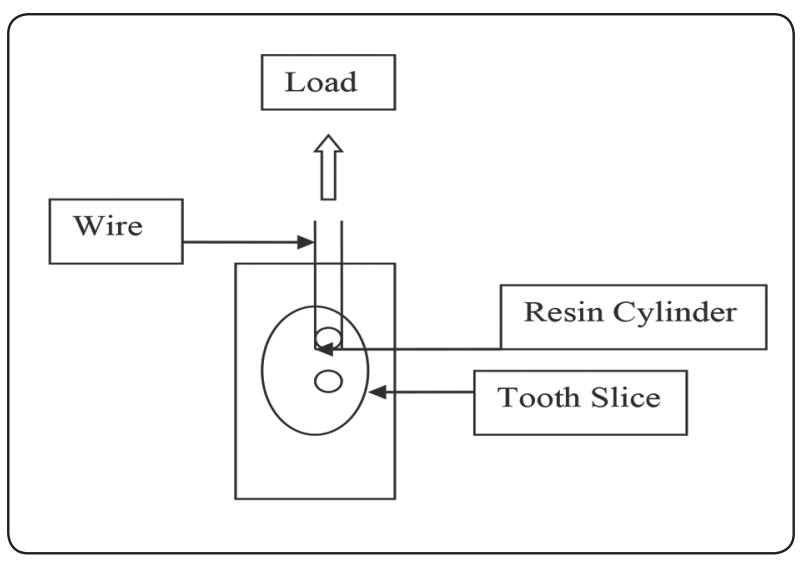

Fig (1) Diagram of the Microshear Bond Test.

\section{Statistical analysis:}

The recorded scores of microleakage were collected, tabulated and statistically analysed using Kruskal-Wallis test to determine the difference between microleakage scores in the three study groups at a 0.05 level of significance. The recorded values of microshear bond strength were collected, tabulated and statistically analysed using One way analysis of variance (ANOVA) and Tukey's tests were used for testing the significance between the means of tested properties of all tested materials. Statistically significant when the $\mathrm{P}$ value $\leq 0.05$.

\section{RESULTS}

\section{Microleakage}

A) The comparison between the mean ranks of microleakage scores at the occlusal surface of the three study groups is shown in table (1) and fig.(2).

The Kruskal-Wallis test was applied to determine the difference between microleakage scores in the three study groups. The Sonic Fill Bulk fill composites demonstrated the least microleakage scores followed by Tetric EvoCeram Bulk fill composite which showed greater scores while the Tetric EvoCeram nanohybrid composite showed the highest microleakage scores.

B) The comparison between the mean ranks of microleakage scores at the gingival surface of the three study groups is shown in table (2) and fig.(3).

The Kruskal-Wallis test was applied to determine the difference between microleakage scores in the three study groups. The Sonic Fill Bulk fill composites demonstrated the least microleakage scores followed by Tetric EvoCeram Bulk fill composite which showed greater scores while the Tetric EvoCeram nanohybrid composite showed the highest microleakage scores.

\section{Microshear bond strength}

The comparison between mean microshear bond strength values in $(\mathrm{MPa})$, of the study groups is shown in table (3) and figure (4).

Microshear bond strength values for Sonic Fill Bulk fill composite was greater than Tetric EvoCeram Bulk fill composite and Tetric EvoCeram nanohybrid composite which showed the least value. 
TABLE (1) Microleakage scores observed at occlusal surface of the three groups.

\begin{tabular}{|c|c|c|c|c|c|c|}
\hline \multicolumn{2}{|c|}{\begin{tabular}{c} 
Group A \\
Tetric EvoCeram nanohybrid \\
\multicolumn{2}{|c|}{ composite }
\end{tabular}} & \multicolumn{2}{c|}{$\begin{array}{c}\text { Group B } \\
\text { Tetric EvoCeram Bulk fill } \\
\text { composite }\end{array}$} & \multicolumn{2}{c|}{$\begin{array}{c}\text { Group C } \\
\text { Sonic Fill Bulk fill composite }\end{array}$} & $P$-value \\
\cline { 1 - 5 } $\begin{array}{c}\text { Mean ranks of } \\
\text { microleakage }\end{array}$ & SD & $\begin{array}{c}\text { Mean ranks of } \\
\text { microleakage }\end{array}$ & SD & $\begin{array}{c}\text { Mean ranks of } \\
\text { microleakage }\end{array}$ & SD & $<0.001$ \\
\hline $17.8^{\mathrm{a}}$ & 0.9 & $13.4^{\mathrm{b}}$ & 1.1 & $8.9^{\mathrm{c}}$ & 1.2 & \\
\hline
\end{tabular}

TABLE (2) Microleakage scores observed at gingival surface of the three groups.

\begin{tabular}{|c|c|c|c|c|c|c|}
\hline \multicolumn{2}{|c|}{$\begin{array}{c}\text { Group A } \\
\text { Tetric EvoCeram nanohybrid } \\
\text { composite }\end{array}$} & \multicolumn{2}{c|}{$\begin{array}{c}\text { Group B } \\
\text { Tetric EvoCeram Bulk fill } \\
\text { composite }\end{array}$} & \multicolumn{2}{c|}{$\begin{array}{c}\text { Group C } \\
\text { Sonic Fill Bulk fill composite }\end{array}$} & P-value \\
\hline $\begin{array}{c}\text { Mean ranks of } \\
\text { microleakage }\end{array}$ & SD & $\begin{array}{c}\text { Mean ranks of } \\
\text { microleakage }\end{array}$ & SD & $\begin{array}{c}\text { Mean ranks of } \\
\text { microleakage }\end{array}$ & SD & $<0.001$ \\
\hline $19.3^{\text {a }}$ & 1.1 & $15.6^{\mathrm{b}}$ & 1.4 & $11.5^{\mathrm{c}}$ & 1.3 \\
\hline
\end{tabular}

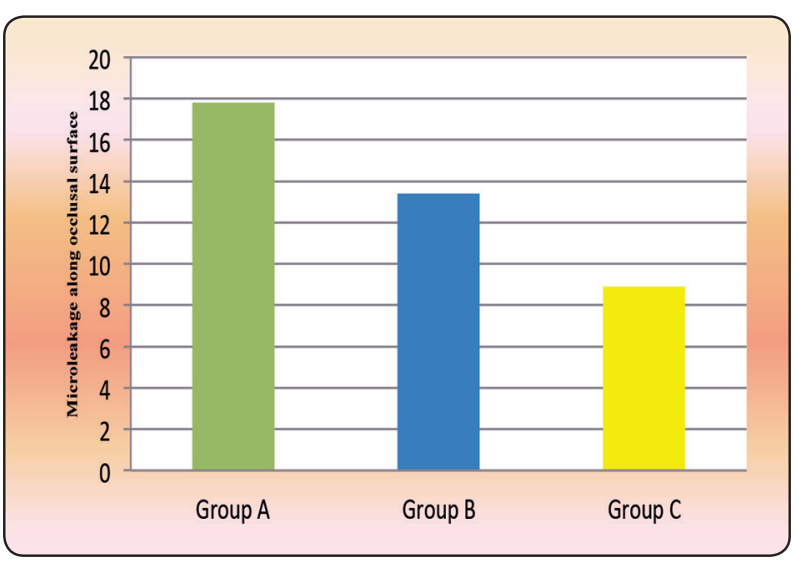

Fig. (2) Bar chart of microleakage at the occlusal surface of the three groups.

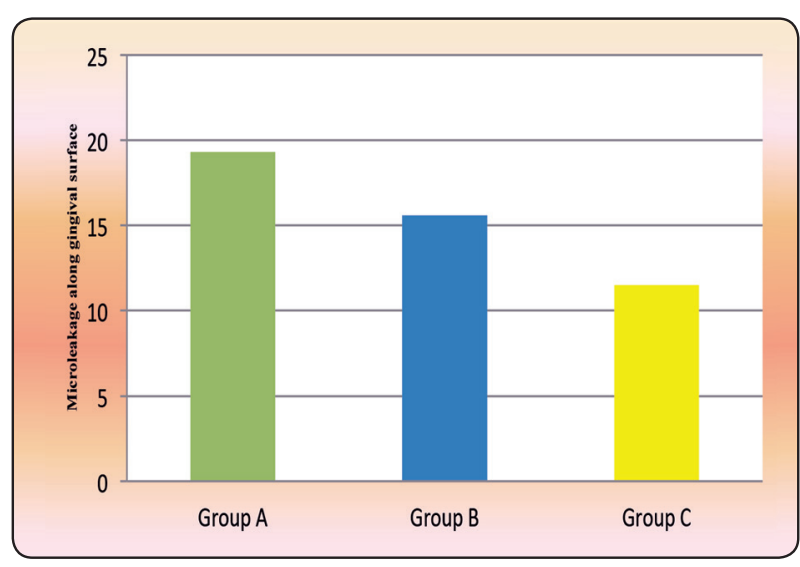

Fig. (3) Bar chart of microleakage at the gingivall surface of the three groups.

TABLE (3) Comparison between microshear bond strength in (MPa) of the tested groups.

\begin{tabular}{|c|c|c|c|c|c|c|}
\hline \multirow{2}{*}{$\begin{array}{c}\text { Group A } \\
\text { Tetric EvoCeram nanohybrid composite }\end{array}$} & \multicolumn{2}{c|}{ Group B } & \multicolumn{2}{c|}{ Group C } \\
\cline { 1 - 5 } Mean & SD & Mean & SD & Mean & SD & \multirow{2}{*}{ P-value } \\
\hline $11.4^{\mathrm{c}}$ & 1.2 & $15.85^{\mathrm{b}}$ & 1.5 & $20.16^{\mathrm{a}}$ & 1.1 & $<0.001^{*}$ \\
\hline
\end{tabular}

*: Significant at P $\leq 0.05$; means with different letters are statistically significantly different according to Tukey's test. 


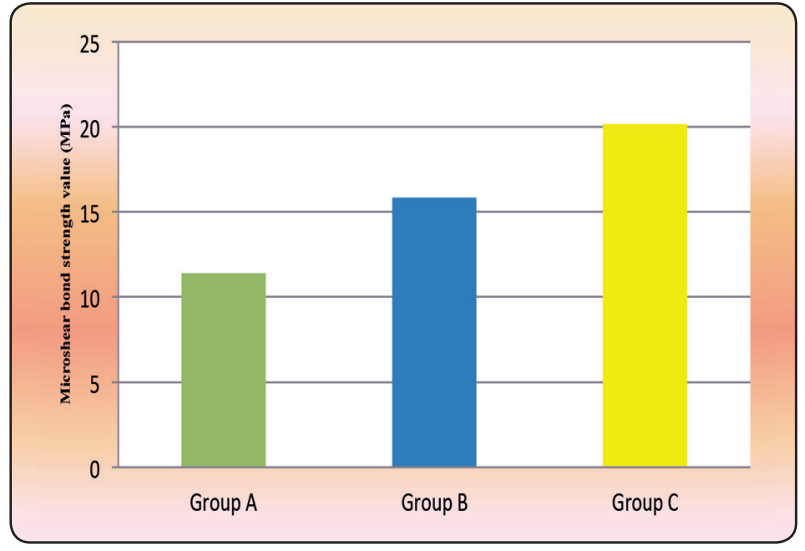

Fig (4): Bar chart of mean microshear bond strength in (MPa) of the tested groups.

\section{DISCUSSION}

Simplified and fast restorative procedures, such as placing resin composite in bulk instead of layering or the use of simplified single component self-etching adhesives instead of multistep selfetching or etch-and-rinse systems, became more and more popular. The efficiency of such simplified restorative procedures and their long-lasting clinical effects are however controversially discussed. ${ }^{8}$

The present study measured the microleakage and microshear bond strength of three different composites.

In testing microleakage, the class $\mathrm{V}$ cavity design was chosen because it had a high $\mathrm{C}$-factor value. It was relatively easy to restore and therefore minimized interoperator variability. It had both enamel and dentinal margins and did not offer any inherent macro-mechanical retention. ${ }^{26}$

The specimens were subjected to thermocycling in order to replicate the intraoral environment because there was a difference in the coefficient of thermal expansion of the restoration and the tooth structure. The resulting mismatch in its value was said to cause fatigue of the bond between the restoration and the tooth, leading to a gap formation, which could lead to microleakage. ${ }^{27}$
The two main established methods that are usually used to study marginal gaps are either dye penetration or scanning electron microscopy (SEM). The dye penetration is somewhat better for testing because (SEM) method requires that the specimens should be subjected to extensive chemical preparations before the scanning process and this may lead to alteration or even destruction of the interfacial zones, and even underestimation of the actual thickness of the hybrid layer. ${ }^{28-30}$

An in-vitro mechanical test became of utmost importance to evaluate and compare bond strengths of adhesive systems to enamel and dentin. The most commonly employed test setup for this purpose were tensile and shear tests. ${ }^{31}$ Shear bond strength tests have been widely used, mainly because of their relative simplicity when compared to tensile bond strength tests, in which it is difficult to align the specimen in the testing machine without creating deleterious stress distribution. ${ }^{32}$ Advantages in shear tests include specimen preparations and simple test protocols. ${ }^{22}$

A new test method using specimens with reduced dimensions has been advocated by some authors ${ }^{25,33}$ as a substitute for the conventional shear test: socalled microbond or microshear bond strength test. According to them, this test would allow for testing of small areas, thus permitting a regional mapping or depth profiling of different substrates and preparing multiple specimens from the same tooth.

In this study, we used Sonic Fill Bulk Fill composite, Tetric EvoCeram Bulk fill composite and Tetric EvoCeram nanohybrid composite and Tetric EvoCeram Bulk fill. The results of this study showed that Tetric EvoCeram nanohybrid composite had the highest scores of microleakage followed by Tetric EvoCeram Bulk fill and Sonic Fill Bulk fill which showed the lowest scores. Also, Sonic Fill composite showed the highest microshear bond strength value in comparison with Tetric EvoCeram Bulk fill and Tetric EvoCeram nanohybrid composite which 
showed the lowest value. This may be contributed to Bulk Fill composites have higher filler content and thus have increased mechanical properties. Due to enhanced translucency and by incorporating a photoactive group in the methacrylate resin, polymerization kinetics are claimed to be better controlled. ${ }^{34}$

Oscillation energy temporarily increases flowability of Sonic Fill composite to achieve precise filling of cavities. An advantage of this composite is the rapid placement through a single increment up to $5 \mathrm{~mm}$ due to reduced polymerization shrinkage, thereby reducing working time and increase mechanical strength. ${ }^{35}$

This may be attributed to the ultra-sonic activation in SonicFill, where it incorporates a highly filled resin with special modifiers that react to sonic energy. As sonic energy is applied through the hand piece, the modifier causes the viscosity to drop (up to 87\%), increasing the flowability of the composite enabling quick placement and precise adaptation to the cavity walls. When the sonic energy is stopped, the composite returns to a more viscous, no slumping state that is perfect for carving and contouring. ${ }^{35}$

\section{CONCLUSION}

Within limitations of this study, we can conclude that:

Sonic Fill Bulk fill composite has the lowest microleakage and the highest microshear bond strength in comparison with Tetric EvoCeram Bulk fill and nanohybrid composite. Due to the sonic energy applied to the Sonic Fill composite which increase the flowability of the material, enabling quick placement and precise adaptation to the cavity walls, the ability to place restorations with single increments and ease to use the Sonic Fill composite can be alternative for posterior restorations.

\section{REFERENCE}

1- Frost PM. An audit on the placement and replacement of restorations in a general dental practice. Prim Dent Care 2002;9:31-36.

2- Bayne S, Thompson J, Swift E, Stamatiades P, Wilkerson M. A characterization of first-generation flowable composites. J Amer Dent Assoc 1998;129:567-77.

3- Lim B, Ferracane J, Sakaguchi R, Condon J. Reduction of polymerization contraction stress for dental composites by two-step light-activation. J Dent Mater 2002;18:436-44.

4- Watts D, Marouf A, Hindi A. Photo-polymerization shrinkage-stress kinetics in resin-composites: methods development. J Dent Mater 2003;19:1-11.

5- Xu X, Ling L, Wang R, Burgess J. Formation and characterization of a novel fluoride-releasing dental composite. $\mathrm{J}$ Dent Mater 2006;22:1014-23.

6- Drummond J. Degradation, fatigue, and failure of resin dental composite materials. J Dent Res 2008;87:710-19.

7- Samuel S, Li S, Mukherjee I, Guo Y, Patel A, Baran G. Mechanical properties of experimental dental composites containing a combination of mesoporous and nonporous spherical silica as fillers. J Dent Mater 2009;25:296-301.

8- Ferracane J. Resin composite state of the art. J Dent Mater 2011;27:29-38.

9- Imazato S, Torii M, Tsuchitani Y, McCabe J, Russell R. Incorporation of bacterial inhibitor into resin composite. $\mathrm{J}$ Dent Res 1994;73:1437-43.

10- Zalkind M, Keisar O, Ever-Hadani P, Grinberg R, Sela M. Accumulation of Streptococcus mutans on light-cured composites and amalgam: an in vitro study. J Esth Dent 1998;10:187-90.

11- Beyth N, Domb A, Weiss E. An in vitro quantitative antibacterial analysis of amalgam and composite resins. J Dent 2007;35:201-06.

12- Jokstad A, Bayne S, Blunck U, Tyas M, Wilson N. Quality of dental restorations. FDI Commission Projects 2-95. Interl Dent J 2001;51:117-58.

13- Sakaguchi R. Review of the current status and challenges for dental posterior restorative composites: clinical, chemistry, and physical behavior considerations. J Dent Mater 2005;21:3-6.

14- Davidson C, Feilzer A. Polymerization shrinkage and polymerization shrinkage stress in polymer-based restoratives. J Dent 1997;25:435-40. 
15- Braga R, Hilton T, Ferracane J. Contraction stress of flowable composite materials and their efficacy as stress-relieving layers. J Am Dent Assoc 2003;134:721-28.

16- Roggendorf M, Kramer N, Appelt A, Naumann M, Frankenberger R. Marginal quality of flowable 4-mm base vs. conventionally layered resin composite. J Dent 2011;39:643-47.

17- Garcia-Godoy F, Kramer N, Feilzer A, Frankenberger R. Long-term degradation of enamel and dentin bonds: 6-year results in vitro vs. in vivo. Dent Mater 2010;26:1113-18.

18- Versluis A, Douglas WH, Cross M, Sakaguchi RL. Does an incremental filling technique reduce polymerization shrinkage stresses? J Dent Res 1996;75:871-78.

19- Schmidt C, Ilie N. The mechanical stability of nano-hybrid composites with new methacrylate monomers for matrix compositions. Dent Mater 2012; 28:152-59.

20- Manne U, Sunil K, Arvind K, Naveen N, Shiny B, Mohan T. Comparing marginal microleakage of three Bulk Fill composites in Class II cavities using confocal microscope: An in vitro study. J Conserv Dent 2015;18: 409-13.

21- Giachetti L. A new method for direct composite restoration of the posterior teeth. J Dent Trib Mid East Afri edition 2014.

22- McDonough W, Antonucci J, He J, Shimada Y, Chiang M, Schumacher G. A microshear test to measure bond strengths of dentin-polymer interfaces. Biomater 2002;23:3603-08.

23- Mc Donough W, Antonucci J, Dunkers J. Interfacial shear strengths of dental resin-glass fibers by the microbond test. Dent Mater 2001;17:492-98.

24- Shimada Y, Iwamoto N, Kawashima M, Burrow M, Tagami J. Shear bond strength of current adhesive systems to enamel, dentin and dentin-enamel junction region. Oper Dent 2003;28:585-90.

25- Shimada Y, Kikushima D, Tagami J. Microshear bond strength of resin bonding systems to cervical enamel. Am J Dent 2003;15:373-77.
26- Ritter AV, Swift EJ Jr, Heymann HO, Sturdevant JR, Wilder AD. An eight-year clinical evaluation of filled and unfilled one-bottle dental adhesives. J Am Dent Assoc 2009;140:28-37.

27- Wahab FK, Shaini FJ, Morgano SM. The effect of thermocycling on microleakage of several commercially available composite Class V restorations in vitro. J Prosthet Dent 2003;90:168-74.

28- Heintze SD. I. The correlation between laboratory tests on marginal quality and bond strength. II. The correlation between marginal quality and clinical outcome. J Adhes Dent 2007;9:77-106.

29- Santini A, Miletic V. Comparison of the hybrid layer formed by Silorane adhesive, one-step self-etch and etch and rinse systems using confocal micro-Raman spectroscopy and SEM. J Dent 2008;36:683-91

30- Ernst CP, Galler P, Willershausen B, Haller B. Marginal integrity of class $\mathrm{V}$ restorations: SEM versus dye penetration. Dent Mater 2008;24:319-27.

31- Tantbirojn D, Cheng Y, Versluis A, Hodges J, Doulgas W. Nominal shear or fracture mechanics in the assessment of composite-dentin adhesion. J Dent Res 2000;79:41-48.

32- Sudsangiam S, Van Noort R. Do dentin bond strength tests serve a useful purpose? J Adhes Dent 1999;1:57-67.

33- Toba S, Veerapravati W, Shimada Y, Nikaido T, Tagami J. Microshear bond strength of adhesive resins to coronal dentin versus the floor of the pulp chamber. Am Dent J 2003;16:51-56.

34- Van Ende A, De Munck J, Van Landuyt KL, Poitevin A, Peumans M, Van Meerbeek B. Bulk-filling of high C-factor posterior cavities: Effect on adhesion to cavity-bottom dentin. Dent Mater 2013;29:269-77.

35- Eunice C, Margarida A, João C, Filomena B, Anabela P, Pedro A. ${ }^{99 \mathrm{~m}} \mathrm{Tc}$ in the evaluation of microleakage of composite resin restorations with SonicFill. An in vitro experimental model. Open J Stomatol 2012;2:340-7. 